\title{
Relationship Between Peroneal Tendons and Anterior Talofibular Ligament
}

\author{
Ahmet Oztermeli, Nazım Karahan \\ Gebze Fatih State Hospital, Corlu State Hospital
}

\begin{abstract}
Background: Anterior talofibular ligament (ATFL) injuries are the most common in ankle torsional injuries. ATFL and peroneal tendons are both important stabilizers of lateral ankle joint. We aimed to evaluate peroneal tendons and ATFL.

Methods: Fifteen nonpaired leg of fresh frozen cadavers were assessed in this study. After harvesting, ATFL diameters were measured at three points by calipers, these are fibular side, intermediate side and talar side. The mean of these three measurements were assessed and tissue a $15 \mathrm{lb}$ load was applied to the peroneal tendons for 10 minutes, and the transverse diameters were measured by folding the thickest part of the tendon in a double-strand.
\end{abstract}

Results: 5 single bundle, 8 double-bundle and 2 three bundles of ATFL were obtained after dissection. . There was no correlation between ATFL diameter, peroneus longus, peroneus brevis and total tendon diameters of peroneus longus and peroneus brevis in women ( $p>0.05)$. A strong correlation was found between ATFL diameter, peroneus longus ( $r$ : 0.95), peroneus brevis ( $r$ : 0.81) and total tendon diameters of peroneus longus and peroneus brevis (r: 0.92) in men.

Conclusion: Relationship between the diameter of the ATFL and peroneal tendons diameters were evaluated and a correlation was observed in males, while no correlation was observed in females.

Keywords: Anterior talofibular ligament, Peroneal tendons, Ankle sprain, Peroneus longus, Peroneus brevis, Cadaveric study.
*Correspondence to Author:

Ahmet Oztermeli

Gebze Fatih State Hospital, Corlu State Hospital

How to cite this article:

Ahmet Oztermeli, Nazım Karahan. Relationship Between Peroneal Tendons and Anterior Talofibular Ligament.American Journal of Orthopedic Research and Reviews, 2021, 4:18.

\section{eScîPub}

eSciPub LLC, Houston, TX USA. 


\section{Introduction}

Ankle torsional injuries are one of the most common injuries in athletes [1]. Anterior talofibular ligament (ATFL) injuries are the most common in ankle torsional injuries but calcaneofibular ligament injuries can be seen too [2]. In this torsional injuries $\% 20-50$ of patients recover from injury with residual sequel [3]. ATFL is a ligament that origins from the distal of the fibula and inserts to the talar neck. It can be single, two or three bundles ${ }^{[4]}$. ATFL is responsible for preventing anterior translation and inversion when the ankle is in plantar flexion.

Perenous longus origins from fibular head and $2 / 3$ proximal fibular shaft, continues beneath the fibula laterally and inserts on medial cuneiform and first metatarsal head. Perenous brevis origins from $2 / 3$ distal fibula, continues anterior to peroneus longus and inserts on fifth metatarsal head. Both muscles are responsible for eversion and plantar flexion of ankle, and also preservation of longitudinal and transverse foot arch. Thus these muscles stabilize the ankle joint and prevent it from torsional injury ${ }^{[5]}$. In the literature there is a study shows that patients with ATFL injury which are treated with perenous tendon rehabilitation and proprioception have better rehabilitation and lesser recurrence rate [6].

Joint stability is due to some factors such as joint capsule, ligaments, tendons, proprioception sense receptors and synergistic functions of these factors ${ }^{[7]}$. It is very important to evaluate the relationships of these factors to prevent athletes from these kind of injuries and to select right treatment option for athletes with torsional joint injuries. Although ankle torsional injuries are commonly treated with non surgical methods, personel treatment options should be considered for athletes engaged in different sports activities ${ }^{[8]}$. One of the surgical methods is nonanatomic tenodesis and in this method perenous tendons are used [9]. On the other hand, there is no study evaluating the relationship between ATFL diameter and perenous tendon diameter in the literature.

In the literature, there is a study showing that ATFL injuries are more common in women athletes than in men athletes ${ }^{[10]}$. Also there are studies showing the relationship between gender and some joint diseases [11; 12; 10; 13]. There is no study evaluating ATFL and peroneal tendon diameters according to gender.

In our study, our first goal was to understand the etiology of ATFL injuries better and the second goal was to get useful information on surgical planning and rehabilitation by evaluating the diameters of ATFL and peroneal tendons .

\section{Material and Methods}

Fifteen nonpaired leg of fresh frozen cadavers were assessed in this study (Table 1). The cadavers were stored at $+4^{\circ} \mathrm{C}$ and the time from death to harvesting was not passed 1 month. The ankles of cadavers had no trauma sequel, osteoarthritis, deformation or any scar of a previous surgery. The range of motion of the ankles which has been assessed were all normal. The harvesting procedures were made by a single surgeon.

\section{Preparation of ATFL}

Lateral ankle incision was made and then all superficial soft tissues including muscles and tendons were removed. Lateral of ankle joint was exposed. 2.5 surgical loops were used for dissection of lateral aspect of the ankle joint (Figure 1). Origin and insertion of ATFL were exposed and harvested at the neutral position of the ankle joint. ATFL diameters were measured at three points by calipers, these are fibular side, intermediate side and talar side. The mean of these three measurements were assessed ${ }^{[4]}$.

\section{Preparation of Peroneal Tendons}

The same ankle incision was used. In the posterolateral aspect of the fibula, just above the superior peroneal retinaculum, peroneus longus and peroneus brevis tendons were exposed, and a closed stripper was used to harvest tendons. After the graft was prepared and cleaned of adherent muscle and adipose tissue 
(Figure 2), a $15 \mathrm{lb}$ load was applied to the tendon for 10 minutes, and the transverse diameters were measured by folding the thickest part of the tendon in a double-strand with a digital goniometer [14].

\section{Statistical analysis}

The results were analyzed by using NCSS 2007 (Number Cruncher Statistical System) (Kaysville, Utah, ABD). Descriptive statistical methods (mean, standard deviation, median, frequency, percentage, minimum, maximum) were used to evaluate the study data. The suitability of the quantitative data for normal distribution was tested with the Shapiro-Wilk test. Student T test was used for comparison of two groups of quantitative variables showing normal distribution. Mann Whitney U Test was used for comparison of two groups of quantitative variables that did not show normal distribution. Pearson correlation test was used to evaluate the relationships between the parameters. Significance was evaluated at least $p<0.05$.

Table 1: Anthroponotic characteristics of cadevers

\begin{tabular}{|l|l|l|}
\hline \multirow{2}{*}{ Age(year) } & Min-Max (Median) & $51-94(76)$ \\
\cline { 2 - 3 } & Mean \pm Sd & $74,07 \pm 12,25$ \\
\hline \multirow{2}{*}{ Sex; $\boldsymbol{n}(\%)$} & Male & $10(66,66)$ \\
\cline { 2 - 3 } & Female & $5(33,33)$ \\
\hline \multirow{2}{*}{ Body Mass Index } & Left & $6(40)$ \\
\cline { 2 - 3 } & Right & $9(60)$ \\
\hline \multirow{2}{*}{ Weight (pound) } & Min-Max (Median) & $18-37(26)$ \\
\cline { 2 - 3 } & Mean $\pm S d$ & $25,48 \pm 6,15$ \\
\hline \multirow{2}{*}{ Height (inch) } & Min-Max (Median) & $92-260(170)$ \\
\cline { 2 - 3 } & Mean $\pm S d$ & $172,53 \pm 55,60$ \\
\hline & Min-Max (Median) & $60-75(69)$ \\
\cline { 2 - 3 } & Mean $\pm S d$ & $67,40 \pm 5,30$ \\
\hline
\end{tabular}

Table 2: Pearson correlation analysis ${ }^{*} \mathrm{p}<0,05{ }^{* *} \mathrm{p}<0,001$

\begin{tabular}{|c|c|c|}
\hline & $r$ & $\mathbf{p}$ \\
\hline \multirow{5}{*}{$\begin{array}{l}\text { ATFL ve Perenous Longus } \\
\text { Mean } \\
\text { Left } \\
\text { Right } \\
\text { Male } \\
\text { Female }\end{array}$} & 0,92 & $0,001^{* *}$ \\
\hline & 0,89 & 0,017 \\
\hline & 0,93 & 0,0001 \\
\hline & 0,95 & $0,0001^{*}$ \\
\hline & 0,61 & 0,27 \\
\hline \multirow{5}{*}{$\begin{array}{l}\text { ATFL ve Perenous Brevis } \\
\text { Mean } \\
\text { Left } \\
\text { Right } \\
\text { Male } \\
\text { Female }\end{array}$} & 0,78 & $0,001^{* *}$ \\
\hline & 0,86 & $0,02^{*}$ \\
\hline & 0,75 & $0,02^{\star \star}$ \\
\hline & 0,81 & $0,004^{* *}$ \\
\hline & 0,47 & 0,42 \\
\hline \multirow{5}{*}{$\begin{array}{l}\text { ATFL ve P.Longus+P.brevis } \\
\text { Mean } \\
\text { Left } \\
\text { Right } \\
\text { Male } \\
\text { Female }\end{array}$} & 0,89 & $0,001^{* *}$ \\
\hline & 0,92 & 0,009 \\
\hline & 0,88 & $0,01^{* *}$ \\
\hline & 0,92 & $0,001^{\star *}$ \\
\hline & 0,65 & 0,23 \\
\hline
\end{tabular}


Ahmet Oztermeli et al., AJORR, 2021, 4:18

Table 3: Diameters of tendons and ligament

\begin{tabular}{|l|l|l|l|l|l|}
\hline & Median $(\mathbf{m m})$ & Left $\mathbf{( m m})$ & Right $(\mathbf{m m})$ & Male $\mathbf{( m m})$ & Female $(\mathbf{m m})$ \\
\hline ATFL & $7,77 \pm 0,54$ & $7,76 \pm 0,52$ & $7,77 \pm 0,58$ & $7,85 \pm 0,61$ & $7,59 \pm 0,34$ \\
\hline Perenous Longus & $6,54 \pm 0,46$ & $6,52 \pm 0,45$ & $6,55 \pm 0,49$ & $6,61 \pm 0,53$ & $6,39 \pm 0,26$ \\
\hline Perenous Brevis & $5,19 \pm 0,31$ & $5,18 \pm 0,26$ & $5,19 \pm 0,35$ & $5,22 \pm 0,37$ & $5,12 \pm 0,17$ \\
\hline $\begin{array}{l}\text { PerenousLongus+ } \\
\text { Perenous Brevis }\end{array}$ & $11,67 \pm 0,78$ & $11,57 \pm 0,77$ & $11,74 \pm 0,82$ & $11,83 \pm 0,88$ & $11,36 \pm 0,47$ \\
\hline
\end{tabular}

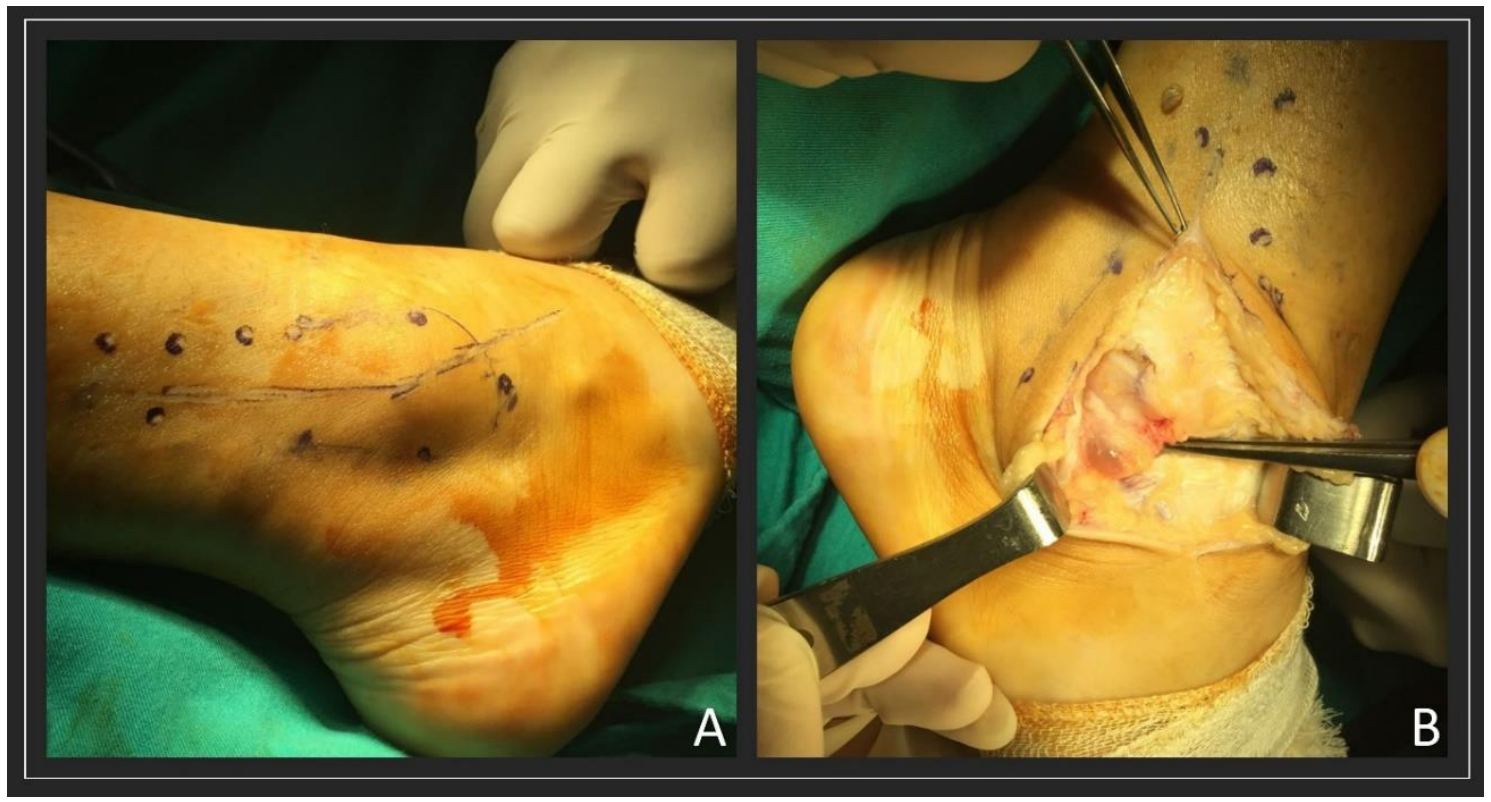

Figure 1: A) Lateral ankle incision B) Exposure of lateral ankle joint

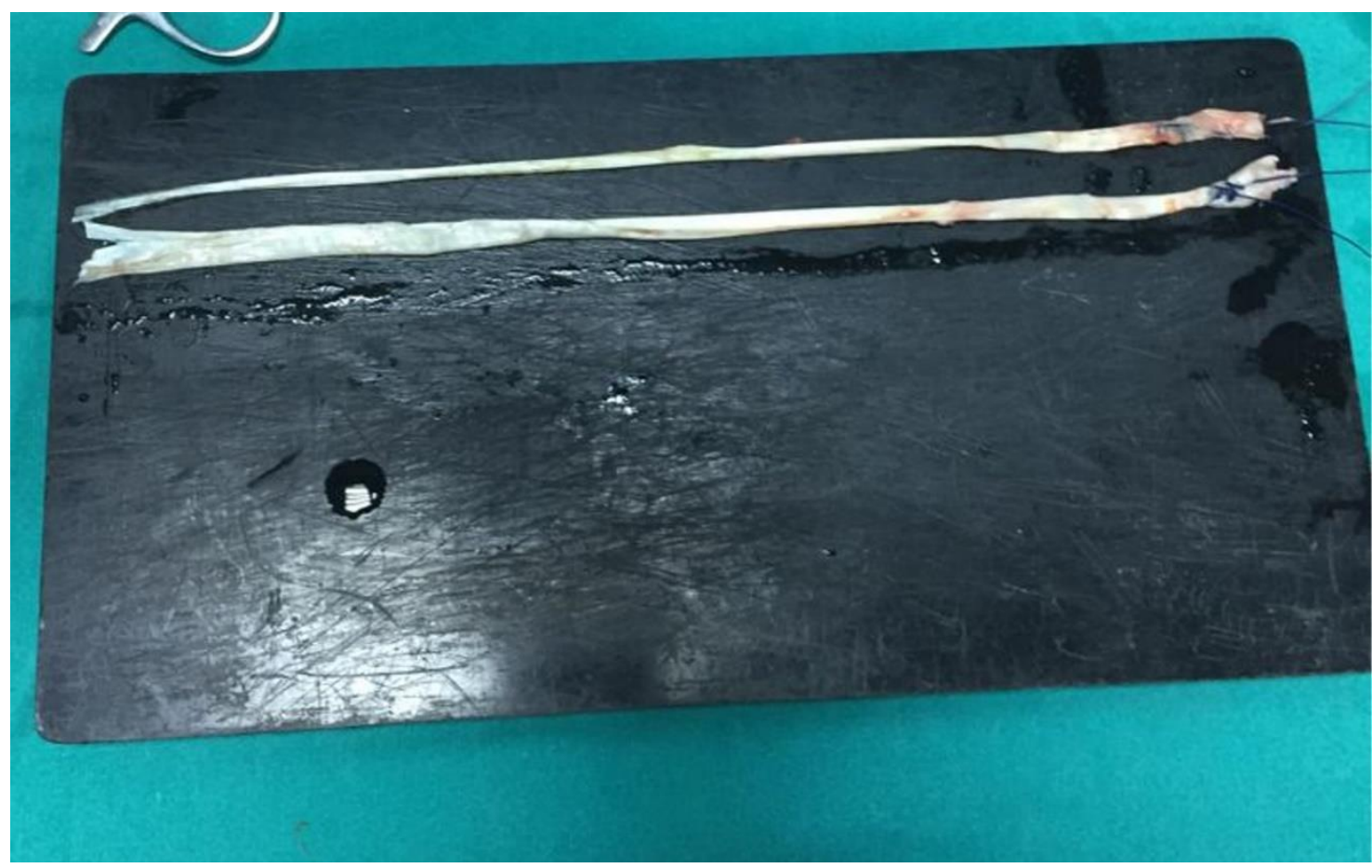

Figure 2: Peroneus longus and brevis grafts were prepared and cleaned of adherent muscle and adipose tissue 


\section{Results}

5 single bundle, 8 double bundle and 2 three bundles of ATFL were obtained after dissection.

When women and men were evaluated together according to the groups, a strong correlation was found between the ATFL diameter and the peroneus longus diameter ( $r: 0.92$ ), and a weaker correlation was observed between ATFL diameter and peroneus brevis diameter ( $r: 0.78$ ).

There was no correlation between ATFL diameter, peroneus longus, peroneus brevis and total tendon diameters of peroneus longus and peroneus brevis in women ( $p>0.05$ ). A strong correlation was found between ATFL diameter, peroneus longus ( $r$ : 0.95), peroneus brevis ( $r$ : 0.81 ) and total tendon diameters of peroneus longus and peroneus brevis ( $r: 0.92)$ in men (Table 2).

When ATFL diameters, peroneus longus tendon diameters, peroneus brevis tendon diameters and total tendon diameters of peroneus longus and peroneus brevis were evaluated, no statistically significant difference was found according to gender ( $p>0.05$ ).

When ATFL diameter, peroneus longus tendon diameter, peroneus brevis tendon diameter, and total tendon diameters of peroneus longus and peroneus brevis were evaluated, no statistically significant difference was found according to the cadaver side (right, left) ( $p>0.05$ ).

When ATFL diameters, peroneus longus tendon diameters, peroneus brevis tendon diameters and total tendon diameters of peroneus longus and peroneus brevis were evaluated, no statistically significant difference was found according to height, weight, body mass index, and age groups ( $p>0.05)$ ( Table 3 ).

\section{Discussion}

We had two important findings in this study. First; the correlation between the diameter of ATFL and the diameters of the peroneal tendons was found in men but not found in women. Second, no significant difference was found between ATFL and peroneal tendon diameters according to gender.
It has been shown that anatomical differences due to gender can cause various disorders in different joints. Although anterior glenohumeral dislocation is more common in men than women, anterior cruciate ligament injury is more common in women than men due to anatomical differences [11; 12]. In the literature, it has been observed that female athletes have more ankle injuries than male athletes [10]. This rate has been shown to be above $25 \%$ in another study [13]. In our study, no correlation was observed in female gender between ATFL diameter and peroneal tendons. When ATFL diameter and peroneal tendon diameters were compared according to gender, no statistically significant difference was found. This suggests that one of the reasons why ATFL injuries are more common in female athletes than in men may be tendon-ligament mismatch rather than diameter thickness.

The surgical treatment of ATFL injury procedures varies such as non-anatomical tenodesis, anatomical ligament repair and anatomical ligament reconstruction [15]. Perenous longus and peroneus brevis tendons are used in the non-anatomical tenodesis. The strength of the reconstructed ligament affects the clinical results [9]. In our study, the correlation was observed between ATFL diameter and peroneal tendon diameters in men, while no correlation was observed in women suggests that the clinical results of these procedures may be more positive in men, but this data should be confirmed by clinical studies.

The anterior talofibular ligament is a ligament that origins from the distal of the fibula and inserts to the talar neck and ATFL is responsible for preventing anterior translation and inversion when the ankle is in plantar flexion. ATFL injury is more common with torsional ankle trauma than calcaneofibular ligament and posterior talofibular ligament injuries [16]. There are variations in the literature regarding the number and thickness of ATFL bundles. The reasons for this variation was stated that it may be caused by differences such as the number of cadavers, 
ethnic difference, gender, body mass index and side (right, left) [17]. Uğur et al. observed $23 \%$ of single bundle, $59 \%$ of double bundles, $18 \%$ of three bunches, ${ }^{[18]}$. In their cadaver study of Milner and Soames, it was observed that $18 \%$ of single bundle, $50 \%$ of double bundles and $32 \%$ of three bundles [19]. Delfault et al. were conducted, $25 \%$ of single bundle and $75 \%$ of double bundles ${ }^{[20]}$. In our study, we found $33 \%$ of single bundle, $53 \%$ of double bundles and $13 \%$ of three bundles, and these findings are consistent with the literature.

There are several methods to measure tendon and ligament diameter. Most commonly used method is to measure the diameter with MRI because it is a non-invasive method and a large number of patients can easily be found [21] However these indirect methods may not show the exact diameters because positional and stress changes can affect the measurement [22]. We chose to measure the tendons in a 15 lb load for 10 minutes to standardized the measurements. We also chose to measure the tendons folding the thickest part of the tendon in a double-strand so the irregular shape of the tendon could not affect the measurement.

There were several limitations in our study. The primary limitations are the small number of cadavers and the old average age of cadavers, which is an important limitation as it may cause variation in ATFL diameter and peroneal tendon diameters. However, the absence of any intraarticular pathology, different tendon and ligament pathologies in the evaluated cadavers reduces the possible measurement changes due to degeneration. Another limitation is that the average results had to be used in the measurement due to the irregular shapes of the measured tendons and ligaments. Last, it was a cadaveric study evaluating only ATFL diameter and peroneal tendon diameters, to get more detailed information, biomechanical and clinical studies are required.

In the light of the information that obtained from our study; the lack of correlation between peroneal tendon diameters and ATFL diameters in women may indicate that non-anatomic tenodesis surgery may negatively affect the results of ATFL surgery, so other techniques should be considered in women. In addition, the fact that there was no significant difference between the ATFL diameter and peroneal tendon diameters according to gender indicates that the reason for the susceptibility to ankle injury in women is not related to these diameters. However, cadaver studies or clinical studies with larger patient numbers are needed to support these conclusions.

\section{Conclusion}

Relationship between the diameter of the ATFL and peroneal tendons diameters were evaluated and a correlation was observed in males, while no correlation was observed in females.

\section{References}

1. Olmsted L.C., Vela L.I., Denegar C.R., Hertel J. Prophylactic ankle taping and bracing: a numbersneeded-to-treat and cost-benefit analysis. J Athl Train. 2004;39(1):95-100. .

2. Staples OS. Ruptures of the fibular collateral ligaments of the ankle: result study of immediate surgical treatment. J Bone Joint Surg Am. 1975;57:101-107. .

3. Smith RW, Reischl SF. Treatment of ankle sprains in young athletes. Am J Sports Med. 1986;14:465-471. . .

4. Edama M, Kageyama I, Kikumoto T, Nakamura M, Ito W, Nakamura et al.Morphological Features of the Anterior Talofibular Ligament by the Number of Fiber Bundles. Ann Anat.2018:216, 6974.

5. Gosselin MM, Haynes JA, McCormick JJ, Johnson JE, Klein SE. The Arterial Anatomy of the Lateral Ligament Complex of the Ankle: A Cadaveric Study. Am J Sports Med. 2019 Jan;47(1):138-143. . .

6. Van PADD, Lubberts B., Verheul C., DiGiovanni $\mathrm{CW}$, Kerkhoffs GMMJ.Rehabilitation after surgical treatment of peroneal tendon tears and ruptures. Knee Surg Sports Traumatol Arthrosc. 2016; 24: 1165-1174.

7. Scott W.N. The knee, volume 1. Mosby Inc.; Saint Louis MO: 1994. .

8. Bekerom MPJ, Kerkhoffs GMMJ, McCollum G, J Calder JDF,van Dijk CN.Management of Acute Lateral Ankle Ligament Injury in the Athlete. Knee Surg Sports Traumatol Arthrosc:2013:21 (6), 1390-5. 
9. Zhang MY, Xu C, Li KH.Finite Element Analysis of Nonanatomic Tenodesis Reconstruction Methods of Combined Anterior Talofibular Ligament and Calcaneofibular Ligament Deficiency. Foot Ankle Int:2011- 32 (10), 1000-8.

10. Wilkerson R., Mason M.A.Differences in Men's and Women's Mean Ankle Ligamentous Laxity. lowa Orthop J. 2000; 20: 46-48.

11. Leroux $T$, Wasserstein $D$, Veillette $C$, Khoshbin $A$, Henry P, Chahal J, Austin P, Mahomed N, OgilvieHarris D. Epidemiology of primary anterior shoulder dislocation requiring closed reduction in Ontario, Canada.Am J Sports Med. 2014 Feb;42(2):442-50.

12. Sutton KM, Bullock JM.Anterior cruciate ligament rupture: differences between males and females. J Am Acad Orthop Surg. 2013 Jan;21(1):41-50. .

13. McCann RS, Kosik KB, Terada M, Beard MQ, Buskirk GE, Gribble PA.ACUTE LATERAL ANKLE SPRAIN PREDICTION IN COLLEGIATE WOMEN'S SOCCER PLAYERS. Int J Sports Phys Ther. 2018 Feb;13(1):12-18.

14. Angthong C, Chernchujit B, Apivatgaroon A, Chaijenkit K, Nualon P, Suchao-in K. The Anterior Cruciate Ligament Reconstruction with the Peroneus Longus Tendon: A Biomechanical and Clinical Evaluation of the Donor Ankle Morbidity. J Med Assoc Thai. 2015;98(. 6):555-560.

15. Burks RT, Morgan J Anatomy of the lateral ankle ligaments. Am J Sport Med 1994:22:72-77. .

16. Davda K, Malhotra K,O'Donnell $P$, Singh D,CullenN.Peroneal tendon disorders. EFORT Open Rev. 2017 Jun; 2(6): 281-292.

17. Raheem OA, O'Brien M.Anatomical review of the lateral collateral ligaments. Anat Sci Int (2011) 86:189-193.

18. Ugurlu, M., Bozkurt, M., Demirkale, I., Comert, A., Acar, H.I., Tekdemir, I., Anatomy of the lateral complex of the ankle joint in relation to peroneal tendons, distal fibula and talus:. a cadaveric study. Eklem hastaliklari ve cerrahisi $=$ Joint diseases . \& related surgery 2010:21,153-158.

19. Milner, C.E., Soames, R.W., Anatomical variations of the anterior talofibular ligament. of the human ankle joint. Journal of anatomy 1997. 191 ( Pt 3), 457-458.

20. Delfaut, E.M., Demondion, X., Boutry, N., Cotten, H., Mestdagh, H., Cotten, A., Multi-fasciculated anterior talo-fibular ligament: reassessment of normal findings. European. radiology2003. 13, 1836-1842.

21. Yılmaz B, Özdemir G, Keskinöz EN, Tümentemur G, Gökkuş K, Demiralp B. Comparing Dimensions of Four-Strand Hamstring Tendon Grafts with Native Anterior and Posterior Cruciate Ligaments. Biomed Res Int. 2016;2016:3795367. .
22. Brushøj, C., Henriksen, B. M., Albrecht-Beste, E., Hölmich, P., Larsen, K., \& Bachmann Nielsen, M. Reproducibility of ultrasound and magnetic resonance imaging measurements of tendon size. Acta Radiologica,2006: 47(9), 954-959. 